\title{
El arte de la poética (Borges: verso a verso)
}

\section{The art of poetry (Borges: verse by verse)}

\section{Selene Fallas}

Universidad de Costa Rica, San José, Costa Rica

\section{RESUMEN}

El presente artículo realiza un análisis (verso a verso) del «Arte poética» de Jorge Luis Borges y, de esta manera, y encontrando los parámetros en algunas de sus obras, se intenta llegar al universo lírico del afamado poeta argentino.

\section{PALABRAS CLAVE}

Arte poética, Borges, poesía latinoamericana

\section{ABSTRACT}

This paper makes an analysis (verse by verse) from The Art of poetry by Jorge Luis Borges, in this way and related the parameter of this poetry with others works from the same author, it tries to explain the lyric universe from this famous argentine poet.

\section{KEYWORDS}

Art of poetry, Borges, Latin-American poetry

\section{Introducción}

El «Arte poética» de Jorge Luis Borges se inscribe en el poemario $E I$ hacedor (1960). El poema está estructurado en versos endecasílabos que forman cuartetos; la rima de este poema es plena y presenta la estructura ABBA. El poema se compone de siete cuartetos de versos endecasílabos. A partir de un análisis (verso a verso) de esta obra y usando como referente al propio Borges para entender la relación de este poema con sus escritos,

\footnotetext{
1 Estudió Literatura en la Universidad Nacional de Costa Rica, hasta el grado de licenciatura. Es egresada de la maestría en Literatura Latinoamericana de la Universidad de Costa Rica (UCR). Ha publicado artículos en revistas de literatura y ha participado en congresos especializados. En 2015 publicó el libro El teatro en Paradiso (un análisis sobre la novela del escritor cubano José Lezama Lima) con la editorial de la UCR. Es profesora en Humanidades y en la carrera de Enseñanza del Castellano y Literatura, Sede del Atlántico, UCR.
} 
se concluye que en este poema se encuentran tres de los pilares que fundamentan la literatura borgeana.

\section{Lectura del poema}

Arte poética

1. Mirar el río hecho de tiempo y agua ${ }^{2} \quad A$

2. Y recordar que el tiempo es otro río $B$

3. Saber que nos perdemos como el río $B$

4. $Y$ que los rostros pasan como el agua $A$

5. Sentir que la vigilia es otro sueño $A$

6. Que sueña no soñar y que la muerte $\quad B$

7. que teme nuestra carne es esa muerte $B$

8. de cada noche que se llama sueño A

9. Ver en el día o en el año un símbolo $A$

10. De los días del hombre y de sus años $B$

11. Convertir el ultraje de los años B

12. En una música, un rumor y un símbolo. $A$

13. Ver en la muerte el sueño, en el ocaso $A$

14. Un triste oro tal es la poesía B

15. Que es inmortal y pobre. La poesía B

16. Vuelve como la aurora y el ocaso. A

17. A veces en las tardes una cara A

18. Nos mira desde el fonfo de un espejo $B$

19. El arte debe ser como ese espejo B

20. Que nos revela nuestra propia cara. A

21. Cuentan que Ulises harto de prodigios $A$

22. Lloró de amor al divisar su ltaca B

23. Verde y humilde el arte es esa Itaca B

24. De verde eternidad no de prodigios. A

25. También es como el río interminable $A$

26. Que pasa y es cristal de un mismo B

27. Heráclito inconstante, que es el mismo $B$

28. Y es otro, como el río interminable. $\quad$ A (1995, p.114).

2 En todos los casos, el subrayado es mío. 
La rima (las palabras subrayadas al final de cada verso) llama la atención, pues no solo repite la alternancia vocálica, sino que repite las palabras finales; sin embargo, en este caso, como lo explica María Ángeles Alvarez: «Este hecho insólito sorprende, pero en ningún momento hace pensar que esos versos sean "pobres"» (1981, p. 117). Esto ocurre porque las palabras finales, aunque son la misma, tienen o usan acepciones diferentes; el significado de la palabra del verso primero no es igual al del verso cuarto (o la del segundo a la del tercero) aunque sea la misma palabra.

El hablante lírico (esto también se subraya en el poema, las tres veces que aparece el pronombre nos) interviene tres veces en el texto, en forma de un sujeto plural, que hace recordar la importancia que daba Borges al proceso de lectura. Según él, lectura y escritura son actos complementarios; de hecho, privilegia el primero:

Me considero esencialmente un lector. Como saben ustedes, me he atrevido a escribir; pero creo que lo que he leído es mucho más importante que lo que he escrito $(2001$, p. 15).

El título «Arte poética» enmarca este poema; el hablante hace una reflexión de lo que para él significa la creación literaria, cómo y para qué escribe. Entonces, y con esa premisa en mente, leamos los primeros versos: «Mirar el río hecho de tiempo y agua». En este primer verso, el río está hecho de tiempo; o sea, la poesía no debe ir a lo referencial en primer término, sino a lo simbólico. En este caso, el símbolo aludido es el río de Heráclito. Las cosas existen para la poesía primero como símbolo y, luego, es que viene lo real o referencial: el agua.

El poema continúa: «Y recordar que el tiempo es otro río», primero el tiempo es un componente simbólico del río, luego adquiere independencia, ya no solo constituye el río, es otro río. Ambos tienen en común la imposibilidad de detenerse o devolverse, transcurren, involuntariamente.

La tercera línea expone: «Saber que nos perdemos como el río». Para explicar esto creo que es importante citar a Borges en su conferencia «El enigma de la poesía», donde, refiriéndose a la metáfora de Heráclito, expone:

Ningún hombre baja dos veces al mismo río. Creo que aquí existe un cierto miedo. En principio solemos pensar en el fluir del río. Pensamos: «Sí, el río permanece, pero el agua cambia». Luego, con una creciente sensación de temor, nos damos cuenta de que nosotros también estamos cambiando, de que somos tan mudables y evanescentes como el río (p. 30).

El ser humano es igual de cambiante que el río; constantemente está cambiando, es otro, a cada instante. 
El primer cuarteto cierra con este verso: «Y que los rostros pasan como el agua». En esta línea el autor recalca este sentido de mutabilidad que tiene el ser humano; alude a los recuerdos, o también podría introducir la creencia que Borges expone en su ensayo «La flor de Coleridge»:

Durante muchos años, yo creí que la casi infinita literatura estaba en un hombre. Ese hombre fue: Carlyle, fue Johanes Becher, fue Whitman, fue Rafael Casinos, fue De Quincey (p. 19).

En este texto Borges trabaja la idea de que un hombre es todos los hombres y que el tiempo es cíclico y va repitiendo la historia, los hombres, los destinos que vuelven incesantemente. Esta es una de los tópicos más recurrentes en la obra de Borges.

El arte poética continúa: «Sentir que la vigilia es otro sueño / que sueña no soñar». Más que retomar el tópico del barroco de «La vida es sueño», es una transformación de esto, pues en el poema de Borges ninguno de los dos espacios es más real. La vigilia es tan ilusoria como el sueño, porque está soñando no soñar; entonces, el sueño soñaría ser vigilia. Ninguno de los dos espacios ofrece menos incertidumbre.

Los siguientes versos sentencian: «Y que la muerte / que teme nuestra carne es esa muerte / de cada noche que se llama sueño». La muerte adquiere un carácter cotidiano y no definitivo, la muerte es el sueño, el descanso. La idea de Plutarco que el mismo Borges cita en «Nueva refutación del tiempo»:

El hombre de ayer ha muerto en el de hoy, el de hoy muere en el de mañana (p. 149).

La continua transformación del ser humano. El hombre está cambiando, no es el mismo a cada instante y ese cambio implica muerte, en cuanto transformación.

«Ver en el día o en el año un símbolo / de los días del hombre y de sus años». El tiempo circular el día se convierte en los días del hombre, de la historia que se repite continuamente días y años. El tiempo es una invención del ser humano y es un símbolo del ser humano de los días y los años, dice Borges:

El tiempo es la sustancia de la que estoy hecho (p. 149).

«Convertir el ultraje de los años / en una música, un rumor y un símbolo». Solo a través del arte se puede sobrevivir al ultraje de los años, se puede transformar en un símbolo. Quien ha creado un símbolo se convierte en ese símbolo y no muere, sino que se mantiene vivo en la literatura, en la memoria, en la creación de otros seres humanos que volverán sobre el 
símbolo creado. Es lo que hace Borges con Heráclito, no es el río de Heráclito, el mismo Heráclito es el río, toma sus características.

«Ver en la muerte el sueño, en el ocaso / un triste oro tal es la poesía». Es tan necesaria la muerte como el sueño, es un descanso. Un ocaso es triste porque está cerca del final del día, porque es un final. Borges en el ensayo «La muralla y los libros» expone:

Esta inminencia de una revelación que no se produce es quizá el hecho estético (1990, p. 13).

Es quizá esta la razón para asociar la poesía con la muerte y el ocaso, porque provocan inminencia, pues es desconocido el misterio que encierran.

Los siguientes versos enuncian: «Que es inmortal y pobre. La poesía / vuelve como la aurora y el ocaso». «Inmortal y pobre». La poesía vuelve como la aurora y el ocaso, es decir, nunca se repite, como no se vuelve a ver el mismo atardecer. Cada lectura de un mismo poema es diferente, no se lee dos veces una obra con los mismos ojos, pero también hay un número finito de interpretaciones. Por eso la poesía es pobre.

«A veces en las tardes una cara / nos mira desde el fondo de un espejo». En las tardes, de nuevo se hace presente el momento del ocaso, la revelación inminente fijada en «una cara» que nos mira desde el fondo de un espejo. Llama la atención el uso de artículos indefinidos. «El arte debe ser ese espejo», la cara del principio no es la misma, es una cara que puede hacer referencia a las influencias literarias, a otros libros; esas son las caras que miran desde el fondo del espejo. Sin embargo, la cara a la que se hace referencia al final es la del autor/lector.

«El arte debe ser como ese espejo / que nos revela nuestra propia cara». El arte permite conocer al ser humano y conocerse, por ende. El arte refleja el alma humana, la revelación no será hecha, solo nos acerca hacia esa revelación, pero no la produce; de ahí que sea hermoso, pues si la revelación se produjera, no sería necesariamente feliz. Como explica Trías:

El arte es fetichista: se sitúa en el vértigo de una posición del sujeto en que «a punto está» de ver aquello que no puede ser visto [...]. Es como si el arte -el artista, su obra, sus personajes, sus espectadores- se situasen en una extraña posición, siempre penúltima a una revelación que no se produce, porque no puede producirse (1996, p. 58).

También en estos versos subyace la idea de que en un libro están todos los libros. Octavio Paz considera respecto al vínculo del lector y el poema que: 
Cada poema es único. En cada obra late, con mayor o menor grado, toda la poesía. Cada lector busca algo en el poema y no es insólito que lo encuentre: ya lo llevaba dentro (1974, p. 216).

Borges, por su parte, tiene una idea parecida, pues también cree en la participación creadora del lector. En «Siete noches» expone:

Cuando leemos un buen poema pensamos que nosotros también hubiéramos podido escribirlo, que ese poema preexistía en nosotros (1980, p. 32).

El poema «Arte poética» continúa: «Cuentan que Ulises, harto de prodigios, / Iloró de amor al divisar su Ítaca». Estos versos remiten a un personaje que está en los pilares de la literatura occidental. Ulises es símbolo del viaje y del regreso. «Cuentan»: el verbo alude directamente al proceso literario; así inició la literatura, contando. El Ilanto no es triste, sino feliz por el regreso. La odisea, el viaje del hombre, que regresa y que es y no es el mismo; han pasado veinte años, ha sido castigado y liberado por los dioses, ha visto morir a todos sus amigos; solo le queda la idea de su origen y el descanso de la muerte. Ulises quiere mantener su destino de mortal, perecer, descansar.

Los siguientes versos: «Verde y humilde. El arte es esa Ítaca de verde eternidad no de prodigios». Y se citará nuevamente a Borges, quien, en una serie de conferencias, publicadas bajo el título de "Siete noches», enunció:

Se supone que la prosa está más cerca de la realidad que la poesía. Entiendo que es un error (1980, p. 17).

La poesía es algo que está cerca, es parte de la cotidianidad, no es un prodigio. El verde es el color de la vida; la humildad se opone a los prodigios. El arte es esa Ítaca a la que se puede volver, verde eternidad, siempre está viva, espera que su rey regrese.

Hay otra idea que podría desprenderse de estos versos; el arte no debe ser truculento, los prodigios cansan. El arte no debe pretender originalidad o hermetismo; la sencillez es lo que hace una obra de arte. El regreso de Ulises está relacionado con la muerte, pues representa el descanso de Ulises.

Las siguientes líneas afirman: «También es como el río interminable / que pasa y queda y es cristal de un mismo Heráclito inconstante, que es el mismo y es otro como el río interminable». En los últimos versos se retoma la metáfora de Heráclito, pero esta vez Heráclito se convierte en un símbolo, no es el río inconstante, es Heráclito el que ha adquirido el valor de un símbolo; el río refleja a Heráclito (es cristal) y cierra con es el mismo y 
es otro. Como el río interminable, de nuevo un hombre es todos los hombres, que transcurren en el río de la historia y el gran libro de la literatura.

\section{Conclusiones}

Tras ver el poema, verso a verso, y a la luz de otras obras del autor donde también expone su poética, se puede concluir que los tres ejes fundamentales que desarrolla Borges en su arte poética son:

1. El proceso de la lectura y la escritura son igualmente importantes; uno no existe sin el otro; siempre que el yo lírico se integra al poema, lo hace en el sujeto plural nosotros: autor y lector.

2. El tiempo transcurre, es inevitable, sigue su curso, lo mismo que todos los destinos, pero el tiempo hace ciclos, igual que el agua. Las palabras regresan en cada verso, pero ya no es la misma palabra. Ulises vuelve a Ítaca, pero no a la misma Ítaca y no el mismo Ulises. El poema comienza con la metáfora de Heráclito y concluye con la misma metáfora, que es la misma y no es la misma.

3. Un hombre es todos los hombres, un libro es todos los libros y de esto da cuenta la literatura que es un proceso dialógico entre autores pasados, presentes y futuros: «Todos los hombres, en el vertiginoso instante del coito, son el mismo hombre. Todos los hombres que repiten una línea de Shakespeare son William Shakespeare», así lo afirma Borges en «Tlön, Uqbar, Orbis Tertius» (1968, p. 76). 


\section{REFERENCIAS BIBLIOGRÁFICAS}

Alvarez, M. (1981). Comentario al «Arte poética» de J. L. Borges. Recuperado de https://dialnet.uniroja.es

Borges, J. L. (1968). Nueva antología personal. México D. F.: Siglo XXI. (1980). Siete noches. Buenos Aires: Emecé Editores.

(1990).Obrascompletas II.Buenos Aires:EmecéEditores. (1995). El hacedor. Madrid: Alianza.

(2001).Artepoética. Seis conferencias. Barcelona:Crítica.

Freud, S. (1994). Obras completas XVII. Buenos Aires: Amorroto Editores.

Guibert, R. (1974). Siete voces: Márquez, Paz, Neruda, Borges, Infante, Asturias, Cortázar. México D. F.: Ediciones Novaro.

Trías, E. (1996). Lo bello y lo siniestro. Barcelona: Ariel.

Recibido: abril de 2016

Aceptado: julio de 2016 